\title{
Improvement of Dye Solar Cell Efficiency by Photoanode Posttreatment
}

\author{
Tanja Ivanovska, ${ }^{1,2}$ Zoran Saponjic, ${ }^{3}$ Marija Radoicic, ${ }^{3}$ Luca Ortolani, ${ }^{4}$ \\ Vittorio Morandi, ${ }^{4}$ and Giampiero Ruani ${ }^{1}$ \\ ${ }^{1}$ Consiglio Nazionale delle Ricerche (CNR), Istituto per lo Studio dei Materiali Nanostrutturati (ISMN), Via Gobetti 101, \\ 40129 Bologna, Italy \\ ${ }^{2}$ Abdus Salam International Centre for Theoretical Physics (ICTP), Strada Costiera 11, 34151 Trieste, Italy \\ ${ }^{3}$ Vinca Institute of Nuclear Sciences, University of Belgrade, P.O. Box 522, 11001 Belgrade, Serbia \\ ${ }^{4}$ Consiglio Nazionale delle Ricerche (CNR), Istituto per la Microelettronica e i Microsistemi (IMM), Via Gobetti 101, \\ 40129 Bologna, Italy
}

Correspondence should be addressed to Tanja Ivanovska; t.ivanovska@bo.ismn.cnr.it

Received 11 April 2014; Revised 14 June 2014; Accepted 18 June 2014; Published 9 July 2014

Academic Editor: Maria da Graça P. Neves

Copyright (C) 2014 Tanja Ivanovska et al. This is an open access article distributed under the Creative Commons Attribution License, which permits unrestricted use, distribution, and reproduction in any medium, provided the original work is properly cited.

\begin{abstract}
The basic concept for efficiency improvement in dye-sensitized solar cells (DSSC) is limiting the electron-hole recombination. One way to approach the problem is to improve the photogenerated charge carriers lifetime and consequently reduce their recombination probability. We are reporting on a facile posttreatment of the mesoporous photoanode by using a colloidal solution of $\mathrm{TiO}_{2}$ nanoparticles. We have investigated the outcome of the different sintering temperature of the posttreated photoanodes on their morphology as well as on the conversion efficiency of the DSSC. The DSSCs composed of posttreated photoanodes at $450^{\circ} \mathrm{C}$ showed an increase in $J_{\mathrm{SC}}$ and consequently an increase in efficiency of $10 \%$. Investigations were made to determine the electron recombination via the electrolyte by the OCVD technique. We found that the posttreatment has the effect of reducing the surface trap states and thus increases the electron lifetime, which is responsible for the increase of the overall cell efficiency.
\end{abstract}

\section{Introduction}

The introduction of the original concept of the dye-sensitized solar cell (DSSC) in 1991 [1] opened up a new line of studies in the field of photovoltaic research and technology. Since then the DSSC undertook the role of an admirable challenger of the first and second generation of solar cells especially on the subject of low energy production process and the use of low cost materials. However, efficiency wise the DSSC is some way off the market available silicon solar cells [2]. In the past 20 years a lot of work and investigation have been put into developing a more efficient and more stable DSSC, developing new concepts, such as the solid state dyesensitized solar cells $[3,4]$, which have most recently evolved into the perovskite solar cells $[5,6]$. In addition, there has been a continuous work towards perfecting and optimizing all constituents of the dye cell, especially the mesoporous photoanode $[7,8]$, the dye $[9,10]$, and the electrolyte [11] or hole conducting material [12].

The mesoporous photoanode has been employed in all types of sensitized solar cells. Regardless of the sensitizing, electrolyte or the hole conducting material (HCM) best performances were given by DSSC devices with a mesoporous $\mathrm{TiO}_{2}$ film acting as a photoanode. However, one of the challenges of improving the efficiency of the DSSC is enhancing the charge separation and electron transport through the mesoporous photoelectrode. Considering this, it is no wonder that there have been numerous papers published over the years on the improvement of the charge injection and transport in the $\mathrm{TiO}_{2}$.

The basic concept for efficiency improvement in the dyesensitized solar cells is limiting the electron-hole recombination. One way to approach the problem is to reduce the resistivity of the mesoporous titania in order to improve the 
photogenerated electron mean free path and consequently reduce the electron-hole recombination probability. Since the mesoporosity of the anatase titania is essential for achieving a high surface area, the most reported methods of improving the conductivity have been the incorporation of carbon nanotubes in the matrix $[13,14]$, or changing the shape or the surface area of the $\mathrm{TiO}_{2}$ nanocrystals $[8,15]$, employing $\mathrm{TiO}_{2}$ nanotubes [16], or even the growth of mesoporous $\mathrm{TiO}_{2}$ single crystals [17].

Another approach is to improve the charge separation and reduce the charge recombination dynamics. There have been investigations in using thin layers of insulating metal oxides on top of the surface of the mesoporous $\mathrm{TiO}_{2}$ photoanode in order to block the recombination $[18,19]$; layers of some rare-earth elements have been used for surface modification due to favorable change in the electronic properties of the photoanode [20]. The mechanism of surface passivation of the photoanode $[21,22]$ has also been used in order to reduce recombination by minimizing the effect of surface traps states.

To this date the most common practice of surface treatment in highly efficient DSSC has been the $\mathrm{TiCl}_{4}$ treatment. A lot has been published on the benefits of the $\mathrm{TiCl}_{4}$ surface treatment of the mesoporous films [23-25]; however, the interpretation of the mechanism by which the improvement is achieved according to the literature is not fully established. There are several different reasons stated for the improved overall efficiency of the cell. Indeed there are extensive studies $[26,27]$ reporting on a series of beneficial effects on the recombination and the surface electric field. There is a correlation in the change of the surface morphology as a result of the surface treatment with change in light harvesting and change in transport and recombination dynamics. To summarize, the effects greatly depend on the starting "quality" of the photoanode. It has been reported that the surface treatment is in fact affecting the porosity of the photoanode; thus there is a fine tuning between the porosity of the treated film and the concentration of the $\mathrm{TiCl}_{4}$ solution [25]. Nevertheless, despite the increase in efficiency there are inevitably some experimental difficulties in working with such volatile material that requires some specific safety and laboratory conditions. The common practice of the treatment is dipping each electrode in a $\mathrm{TiCl}_{4}$ water solution held at $70-80^{\circ} \mathrm{C}$ for $30 \mathrm{~min}$, for best and reproducible results reusing the solution are not advised $[24,28]$. Additionally preparing a $\mathrm{TiCl}_{4}$ water solution of the wanted concentration is a very delicate procedure taking into account that diluting $\mathrm{TiCl}_{4}$ can cause formation of $\mathrm{HCl}$ fumes. This is a relatively complicated part for a surface treatment of the photoanode considering the simplicity of the preparation and assembly of the complete dye cell.

In this paper we are proposing the use of a simple surface treatment via colloidal solution of $\mathrm{TiO}_{2}$ nanoparticles. We have investigated the effects of the $\mathrm{TiO}_{2}$ photoanode surface treatment by drop casting colloidal solution of $5 \mathrm{~nm} \mathrm{TiO}$ nanoparticles in order to improve the efficiency of DSSC using a time-efficient and low material consumption technique. Spectroscopic and morphological characterizations were performed to investigate the morphological changes of the photoanode. Electrical characterization was performed by means of solar cell current-voltage characterization and open circuit voltage decay measurements. The effects of surface trap states modification as the main reason behind the efficiency changes of the solar cells are discussed.

The aim of this work was to investigate a facile posttreatment of the photoanode that could substitute the $\mathrm{TiCl}_{4}$ treatment, providing a comparable conversion efficiency improvement. In respect with this objective we would like to note that our intention was not focused towards competing with record efficiency DSSCs but rather in understanding the physics behind the obtained results.

\section{Materials and Methods}

2.1. Colloidal Solution Preparation. The colloidal solution of $\mathrm{TiO}_{2}$ nanoparticles was prepared according to adapted procedure of Rajh et al. [29]. $6 \mathrm{~mL}$ of $\mathrm{TiCl}_{4}$ cooled to $-20^{\circ} \mathrm{C}$ was added drop-wise to $200 \mathrm{~mL}$ Milli-Q deionized water, held at $4^{\circ} \mathrm{C}$ under vigorous stirring and then kept at this temperature for half an hour. Due to the formation of $\mathrm{HCl}$ during the hydrolysis of $\mathrm{TiCl}_{4}$, the starting $\mathrm{pH}$ of the colloidal solution was 0 . By applying dialysis ( 3 days) of the obtained solution against water, which was changed daily, the $\mathrm{pH}$ increased to $\mathrm{pH} \sim 3$ and slow particle growth was achieved ( $d \sim 4.5 \mathrm{~nm}$ ). The final concentration of $\mathrm{TiO}_{2}$ colloids was determined from Ti(IV)-peroxide complex [30, 31].

All the chemicals except for the ones stated otherwise were acquired from Aldrich, Fluka, and used without further purification.

2.2. DSSCs Preparation. Fluorine doped tin oxide (FTO) substrates (Solaronix TCO 22-7, $7 \Omega /$ sq) were cut in size $1.8 \times 2 \mathrm{~cm}$, washed in successive ultrasonic baths of deionized water, acetone, and isopropanol, and dried with $\mathrm{N}_{2}$ gas flow. The $\mathrm{TiO}_{2}$ mesoporous films were deposited by doctor blade technique. The $\mathrm{TiO}_{2}$ paste was made suspending P25 nanoparticles and PEG 2000 in water, adding Triton X100 to adjust the viscosity and improve adhesion to the substrate. The films were burned at $450^{\circ} \mathrm{C}$ for 40 minutes. The thickness of the films was measured by step profilometer. The mesoporous films were kept in air, in dark, and prior to colloidal treatment or before dipping in dye for the untreated electrodes; the films were reburned at $450^{\circ} \mathrm{C}$ for $15 \mathrm{~min}$ to remove any moisture. The colloidal treatment of $0.12 \mathrm{M}$ was drop-casted onto the films; after $1 \mathrm{~min}$ the excess was removed and the films were left to dry in air. After drying they were sintered and subsequently cooled down to $80^{\circ} \mathrm{C}$ before being dipped in to $9 \mathrm{mM}$ solution of N3 dye (Solaronix) in ethanol.

The substrates were left overnight in the dye solution in dark, after which they were washed with ethanol and dried for few minutes in air. The counter electrode was a FTO glass substrate coated with platinum precursor solution (Platisol T, Solaronix) which was burned at $450^{\circ} \mathrm{C}$ for $20 \mathrm{~min}$. The cell was assembled using $60 \mu \mathrm{m}$ surlyn spacer. Ionic liquid electrolyte consisting of 0.6 M BMII (1-butyl-3methylimidazolium iodide), $0.1 \mathrm{M} \mathrm{LiI}, 0.05 \mathrm{M} \mathrm{I}_{2}$, and $0.5 \mathrm{M}$ 
TBP (4-tert-butylpyridine) in acetonitrile was inserted in to the cell before complete sealing.

To ensure reproducibility, several batches of cells were made, with at least 2 identical cells per batch with the respective posttreatment.

Investigation was also made on cells prepared using a Solaronix AN-50 electrolyte, with mesoporous photoanode thickness around $8 \mu \mathrm{m}$. Where stated, a compact $\mathrm{TiO}_{2}$ layer was deposited via spin-coating a precursor solution of $0.25 \mathrm{M}$ TAA (diisopropoxytitanium bis (acetylacetonate) solution) in ethanol. The compact films were formed by burning the coated substrates at $490^{\circ} \mathrm{C}$ for 1 hour.

2.3. Spectroscopy. Raman spectroscopy measurements were made with a micro-Raman Renishaw 1000 system with $\lambda_{\text {ex }}=$ $632.8 \mathrm{~nm}$ in confocal mode. The acquisition time was $40 \mathrm{~s}$ in order to achieve a relatively good signal to noise ratio using a power density of $2 \times 10^{3} \mathrm{~W} / \mathrm{cm}^{2}$. As a control sample we used a $\mathrm{TiO}_{2}$ mesoporous film made from colloidal paste of P25 nanocrystals.

Absorption measurements were performed on dye solution desorbed from films with and without posttreatment using a JASCO V-550 UV-Vis spectrometer. FTO substrates coated with mesoporous $\mathrm{TiO}_{2}$ films of $1 \mathrm{~cm}^{2}$ were posttreated and the films with the same thickness were dipped and left overnight in a $9 \mathrm{mM}$ ethanol solution of $\mathrm{N} 3$ dye. After removing the substrates from the solution and washing off the excess dye with ethanol the films were left to dry in dark and then the dye was desorbed from the films placing them in sealed containers with equal volumes of a $0.1 \mathrm{M}$ solution of $\mathrm{NaOH}$ in water.

2.4. Morphology. Thickness measurements were conducted using a step profilometer. Investigation of the thickness and roughness change after colloidal treatment and sintering procedure at 150,350 , and $450^{\circ} \mathrm{C}$ was performed on samples similar to those used in cell configuration, that is, mesoporous $\mathrm{TiO}_{2}$ films of $1 \mathrm{~cm}^{2}$ deposited onto FTO substrates. The thickness was measured before and after the colloidal treatment.

Scanning electron microscope (SEM) imaging was made to study the surface of the films. The experiments were performed using a LEO 1530 FE-SEM, with a Schottky emitter, operated at $10 \mathrm{keV}$ accelerating voltage, equipped with Everhart-Thornley and In-lens detectors for secondary electrons and Oxford INCA EDS X-Ray spectrometer.

2.5. Device Characterization. Current voltage characteristics of the cells were measured with Keithley 236 source-measure unit under simulated AM1.5 illumination of $100 \mathrm{~mW} / \mathrm{cm}^{2}$ Abet Technologies Sun 2000 Solar Simulator. The simulator was calibrated using a silicon reference cell with KG5 filter, and the cells were masked with a sample holder which disabled any light piping effects.

Open circuit voltage decay (OCVD) measurements were performed using a Keithley 2400 SourceMeter, exposing the cell to full sunlight for $5 \mathrm{~s}$ to achieve steady state; then the illumination was interrupted by closing the shutter; the time interval between points was $50-100 \mathrm{~ms}$.

\section{Results and Discussion}

Primarily the investigation on the coating of the photoanode led to establishing that the optimal concentration of the colloidal solution was $0.12 \mathrm{M}$. Increasing the concentration leads to cracking and peeling of the films. The effect of further decoration of the mesoporous films by successive coatings led to similar results. This was a consequence of tightly packed areas of the $\mathrm{TiO}_{2}$ film surface that were acting as a compact layer which when dried, shrank, causes strain between the formed surface film and the rest of the mesoporous matrix which led to cracking and detaching from the substrate.

Employing a posttreatment of the $\mathrm{TiO}_{2}$ mesoporous photoanode films requires a sintering process in order to remove any residual water or impurities from the mesoporous matrix and film surface, to ensure an efficient dye loading. However, to try and understand the effect of the sintering temperature on the size of the colloidal $\mathrm{TiO}_{2}$ nanocrystals, as well as, on the morphology and porosity of the mesoporous films, we performed systematic investigations using profilometric measurements, Raman spectroscopy, and SEM imaging. Furthermore to establish whether the surface treatment was preliminary changing the effective surface area of the mesoporous photoanode UV-Vis absorption spectra were also measured.

To investigate the nanocrystalline size and morphology of the films with regard to the temperature treatment, $0.12 \mathrm{M}$ of $\mathrm{TiO}_{2}$ colloidal solution was drop-casted onto clean glass slides. The samples were sintered on a hot plate in air for $20 \mathrm{~min}$ at different temperatures of 150,350 , and $450^{\circ} \mathrm{C}$. As a reference $\left(\mathrm{P} 25 @ 450^{\circ} \mathrm{C}\right)$ a film prepared by using the $\mathrm{P} 25 \mathrm{TiO}_{2}$ paste (see Section 2.2) was used.

Raman measurements were performed to investigate the crystalline size. The data of the Raman spectra are summarized in Table 1. Estimations of the crystalline size were made according to Kelly et al. [32] experimental results. The analysis was done on the basis of the two most intense anatase Eg modes around $145 \mathrm{~cm}^{-1}$ and $640 \mathrm{~cm}^{-1}$. Extracting the values for the full width half maximum (FWHM) of the peaks ( $\Gamma_{1}$ and $\Gamma_{2}$, resp.), using the available data, we have observed that by increasing the annealing temperature the size of the nanocrystals increases, as a consequence of nanocrystalline coalescence during the burning process. Here we note that the Raman measurement is essentially a measurement of the crystalline core and not the nanoparticle itself, which in turn could be few nanometers larger.

The colloidal posttreatment of the mesoporous $\mathrm{TiO}_{2}$ photoanodes induces a slight thickness change. For the films between 13 and $15 \mu \mathrm{m}$, we observed an increase of $0.2-$ $0.5 \mu \mathrm{m}$, depending on the sample. We are reporting on an interval rather than a fixed thickness increase, as a result of multiple measurements on large number of substrates, also taking into account the difficulty of precise measurement on films of $1 \mathrm{~cm}^{2}$ surface with such roughness. In the further investigations this difference in thickness was compensated 
TABLE 1: Raman shift- $\omega$ and FWHM- $\Gamma$ of the of the Eg modes around $145 \mathrm{~cm}^{-1}$ and $640 \mathrm{~cm}^{-1}$ nanocrystalline size $(\Phi)$ dependence on the sintering temperature, estimated from the FWHM.

\begin{tabular}{|c|c|c|c|c|c|c|c|c|}
\hline \multirow{3}{*}{$T\left({ }^{\circ} \mathrm{C}\right)$} & \multicolumn{6}{|c|}{ Colloidal nanoparticles } & \multirow{2}{*}{\multicolumn{2}{|c|}{$\begin{array}{l}\mathrm{P} 25 \\
450\end{array}$}} \\
\hline & \multicolumn{2}{|c|}{150} & \multicolumn{2}{|c|}{350} & \multicolumn{2}{|c|}{450} & & \\
\hline & $\mathrm{cm}^{-1}$ & $\Phi(\mathrm{nm})$ & $\mathrm{cm}^{-1}$ & $\Phi(\mathrm{nm})$ & $\mathrm{cm}^{-1}$ & $\Phi(\mathrm{nm})$ & $\mathrm{cm}^{-1}$ & $\Phi(\mathrm{nm})$ \\
\hline$\overline{\omega_{1}}$ & $157.9 \pm 0.9$ & & $149.8 \pm 1.2$ & & $146.7 \pm 1.6$ & & 144.1 & \\
\hline$\Gamma_{1}$ & $39.7 \pm 0.3$ & $3.2 \pm 0.2$ & $17.9 \pm 2.9$ & $7.0 \pm 1.0$ & $15.6 \pm 2.3$ & $8.0 \pm 1.1$ & 9.6 & $>23$ \\
\hline$\omega_{2}$ & $640.6 \pm 0.2$ & & $640.9 \pm 2.1$ & & $641.9 \pm 0.6$ & & 639.0 & \\
\hline$\Gamma_{2}$ & $80.8 \pm 1.8$ & $3.4 \pm 0.1$ & $52.5 \pm 0.6$ & $5.1 \pm 0.1$ & $38.3 \pm 7.5$ & $7.7 \pm 1.9$ & 25.5 & $>17$ \\
\hline
\end{tabular}

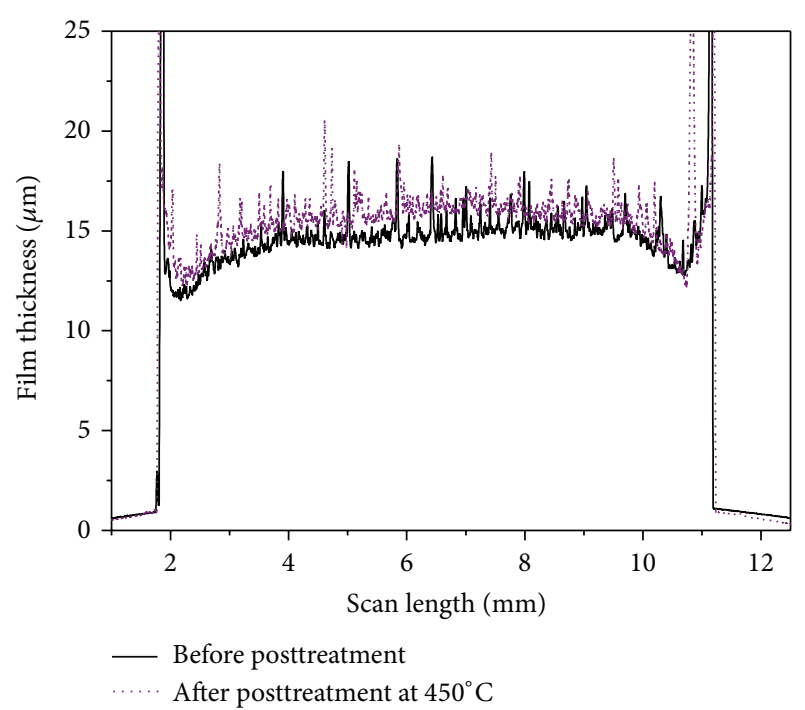

FIGURE 1: Surface profile of the $\mathrm{TiO}_{2}$ film before (black solid line) and after (purple dotted line) the colloidal posttreatment sintered at $450^{\circ} \mathrm{C}$.

by using a few tenths of micron ticker films for the untreated photoanode. Additionally the $2 \mathrm{D}$ surface profile did not indicate any difference in the roughness of the samples as seen from Figure 1.

Figure 2 shows secondary electrons SEM images of the untreated and posttreated photoanode at $450^{\circ} \mathrm{C}$. At this resolution we did not observe any difference between the surface morphologies.

Posttreatment of the photoanode with nanoparticles of around $5 \mathrm{~nm}$ can impact the surface volume ratio of the mesoporous films. Any change in efficiency of the DSSC could be attributed to the higher or lower dye loading of the photoanodes. To study the effect of the posttreatment of the photoanode at the investigated temperatures we performed absorption measurements. The UV-Vis absorption spectra of the dye solutions desorbed from untreated and posttreated mesoporous films are shown in Figure 3.

It can be observed that there is a small increase (around $5 \%$ ) in the integrated dye absorption of the films treated at 150 and $350^{\circ} \mathrm{C}$; in contrast, the film with surface treatment at $450^{\circ} \mathrm{C}$ does not show practically any difference in dye absorption with respect to the untreated film. This increase could be expected taking into account the smaller nanoparticle
TABLE 2: Photovoltaic parameters of the DSSCs with $J-V$ curves shown in Figure 4(a).

\begin{tabular}{lcccc}
\hline Photoanode type & $J_{\mathrm{SC}}\left(\mathrm{mA} / \mathrm{cm}^{2}\right)$ & $V_{\mathrm{OC}}(\mathrm{V})$ & $\mathrm{FF}(\%)$ & $\eta(\%)$ \\
\hline No posttreatment & -7.45 & 0.66 & 62.99 & 3.10 \\
$150^{\circ} \mathrm{C}$ & -7.36 & 0.69 & 60.21 & 3.06 \\
$350^{\circ} \mathrm{C}$ & -7.62 & 0.68 & 58.01 & 3.01 \\
$450^{\circ} \mathrm{C}$ & -8.23 & 0.69 & 60.92 & 3.46 \\
\hline
\end{tabular}

size in the coating films sintered at lower temperatures. The surface treatment in this case is increasing the effective surface area of the mesoporous film, hence increasing the dye absorption. We performed absorption measurements on several batches of untreated and posttreated films to substantiate the observed absorption trend. We found that even though the absorption increase for the low temperature sintered films was small $(5 \pm 1.5 \%)$, the tendency of this increase and the lack of difference between the untreated and films treated at $450^{\circ} \mathrm{C}$ remained.

According to the performed measurements and investigations on the posttreated $\mathrm{TiO}_{2}$ films, it can be concluded that the surface treatment is only marginally increasing the thickness of the films without changing the surface morphology and slightly increasing the surface/volume ratio (S/V) only for low temperature annealed samples; while for those sintered at higher temperature $\left(450^{\circ} \mathrm{C}\right)$ there is no distinction in the $\mathrm{S} / \mathrm{V}$ with the untreated films.

Electrical investigations were made on complete $1 \mathrm{~cm}^{2}$ dye-sensitized solar cell devices employing posttreated photoanodes annealed at different temperatures. The aim was to understand the effect that the colloidal posttreatment would have on the efficiency of the cell. The currentvoltage characteristics of the prepared cells are shown in Figure 4(a). The parameters of the cells in Figure 4(a) are shown in Table 2 . The highest conversion efficiency has been observed in DSSC device with the colloidal treatment of the photoanode sintered at $450^{\circ} \mathrm{C}$, showing an improvement in efficiency larger than $10 \%$ with respect to the bare one. This improvement is mainly associated with the increase in the photocurrent of the cell. The increase in the $I_{\mathrm{SC}}$ depends on the light harvesting efficiency (LHE) and/or the collection and injection efficiency [33]. However, the investigation done on the dye absorption of the photoanode indicates that there are no extra dye molecules absorbed to account for an increase of $10 \%$. Furthermore, taking into account only the 


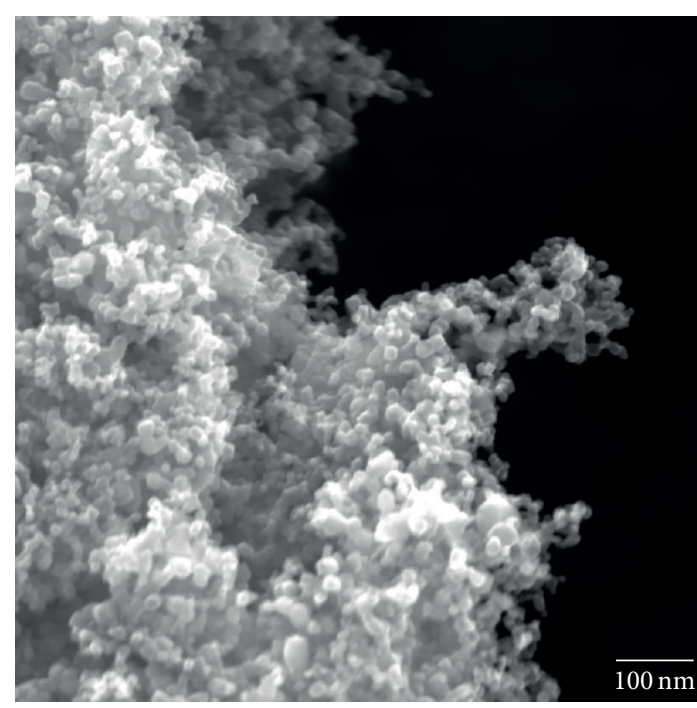

(a)

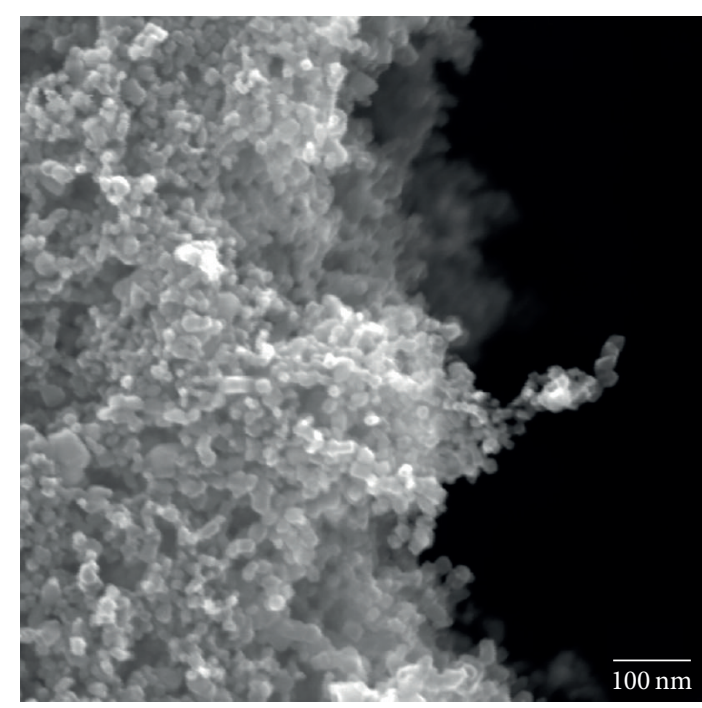

(b)

FIGURE 2: Secondary electrons SEM images of mesoporous $\mathrm{TiO}_{2}$ photoanodes: (a) untreated photoanode; (b) posttreated photoanode sintered at $450^{\circ} \mathrm{C}$

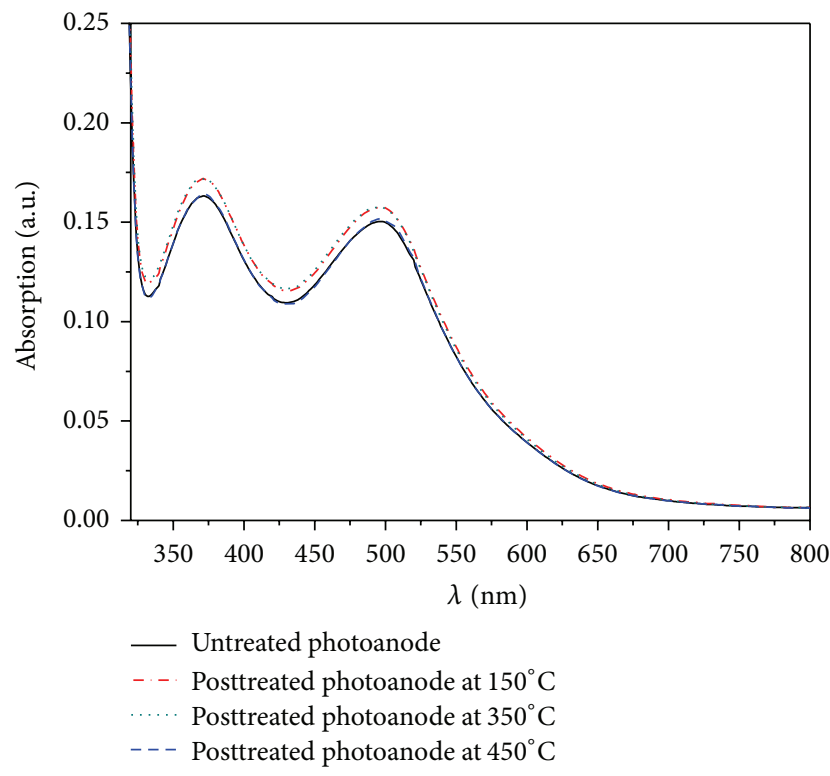

FIgURE 3: Absorbance of aqueous solution of N3 dye desorbed from $\mathrm{TiO}_{2}$ mesoporous films; untreated photoanode (black solid line) and the posttreated photoanodes at $150^{\circ} \mathrm{C}$ (red dot-dash line), $350^{\circ} \mathrm{C}$ (green dotted line), and $450^{\circ} \mathrm{C}$ (blue dashed line).

UV-Vis absorption measurements one would expect to find a slight increase in the photocurrent (about $5 \%$ ) for the cells with photoanode treatment at $150^{\circ} \mathrm{C}$ and $350^{\circ} \mathrm{C}$, but in fact the efficiency of these cells is slightly lower than for the cells with the untreated photoanode, as seen from Figure 5.

Apparently there is no significant correlation among the increase in the dye absorption (the surface/volume ratio) and the conversion efficiency increase in these cells, allowing us to eliminate the LHE as a reason for the efficiency increase.
Furthermore, low sintering temperature can also affect the conductivity of the $\mathrm{TiO}_{2}$ photoanode by slowing down the charge transport probably as a consequence of the low interconnectivity of the surface nanoparticles to the mesoporous matrix. In the case of low temperature annealed photoanodes, these two effects, LHE increase and worse electron transport would compensate each other, and consequently the cells with untreated and the cells with posttreated photoanode have similar conversion efficiency.

If we consider the difference in the dark current shown in Figure 4(b), we can notice a very slight shift of the dark current onset, hence the increase in the $V_{\mathrm{OC}}$ of $0.01-0.02 \mathrm{~V}$. According to Ito et al. [28], the suppression of the dark current for the posttreated photoanodes would indicate a decrease of the electron trap sites on the $\mathrm{TiO}_{2}$ surface. This argument would suggest that the photoanode posttreated at $150^{\circ} \mathrm{C}$ has the smallest surface trap density. However if we take into account the steepness of the slopes, where the steepest slopes indicate lowest series resistance in the cell [34], we can agree with the assumption that, in fact for the $150^{\circ} \mathrm{C}$ and $350^{\circ} \mathrm{C}$ treated samples, there is an issue of the electron transport through the photoanode due to interconnectivity of the nanoparticles, which in turn is suppressing the cell efficiency regardless of the higher dye absorption and possibly lower surface trap sites of these photoanodes.

This is only a qualitative notification since the series resistance depends not only on the electron transport in the photoanode but also on the transport in the FTO substrate, electron transfer across the interface of electrolyte/Pt-FTO, and the electrolyte diffusion time [35]. Nevertheless for the means of this investigation, due to the identical construction elements of the cells and changes only in the photoanode surface, we can deem this result relevant. It is reasonable to suggest that the increase in the $I_{\mathrm{SC}}$ /efficiency is a result of either change in the collection or injection efficiency. 


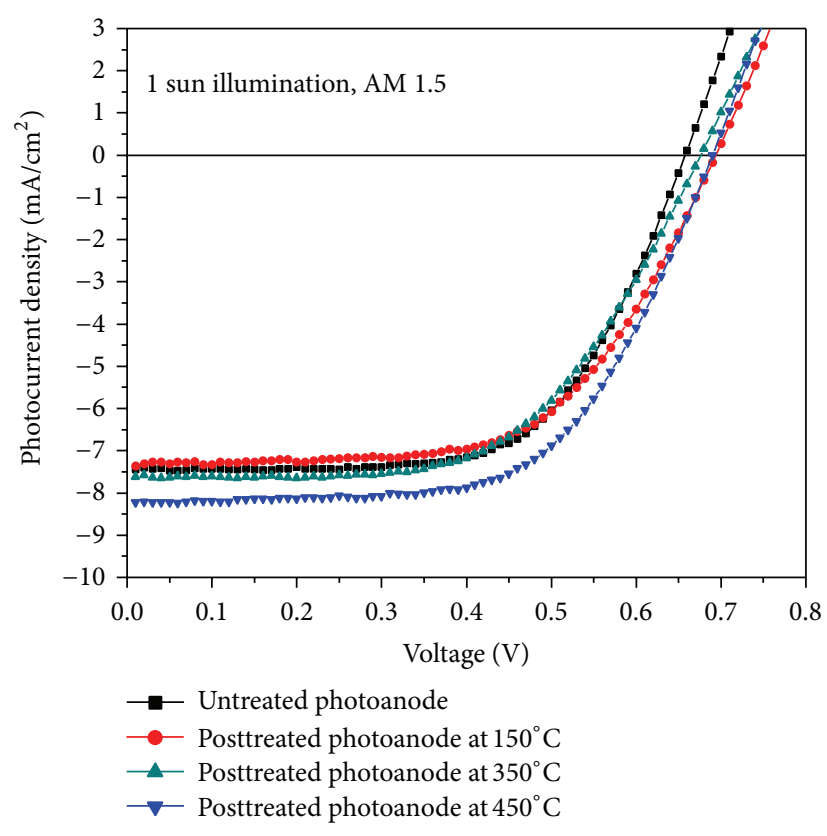

(a)

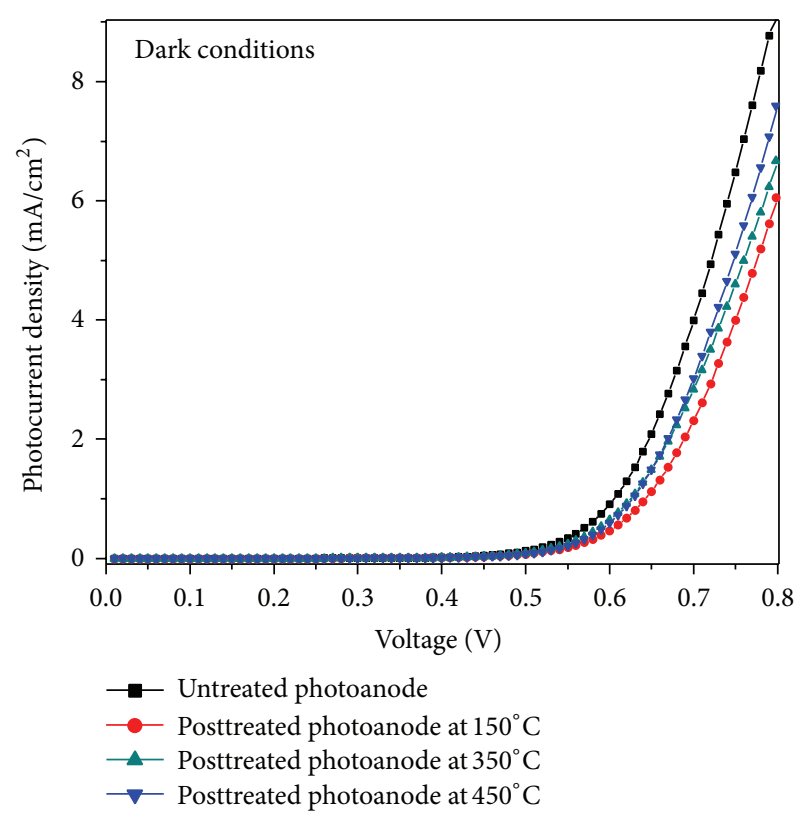

(b)

FIGURE 4: Photocurrent density-voltage curves measured under (a) AM 1.5 simulated light intensity at $100 \mathrm{~mW} / \mathrm{cm}^{2}$ (1 sun); (b) dark conditions, of DSSCs with untreated photoanode (black full square) and posttreated photoanodes with colloidal treatment at $150^{\circ} \mathrm{C}$ (red full circle), $350^{\circ} \mathrm{C}$ (green full triangle), and $450^{\circ} \mathrm{C}$ (blue full inverted triangle).

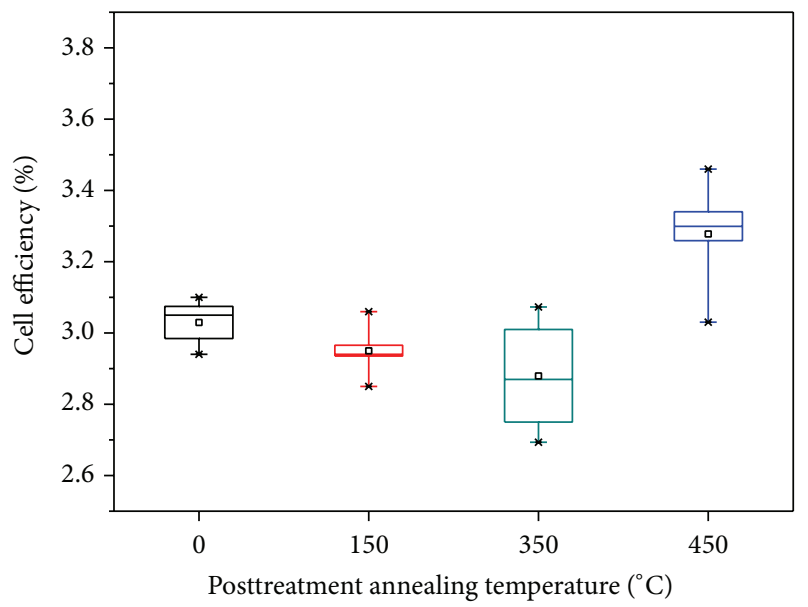

FIGURE 5: Box plots of the dependence of the efficiency of the DSSCs on the photoanode posttreatment temperature.

In order to have an increase in the rate and efficiency of electron injection from the photoexcited dye into the $\mathrm{TiO}_{2}$ one should observe a downward shift of the conduction band which would result in a lower $V_{\mathrm{OC}}$, since the band edge would become closer to the redox potential. This has not been observed in our investigation taking into account the solar cells characteristics. According to Sommeling et al. this downward shift effect could be balanced out if the surface treatment also strongly reduces the recombination rate; hence no change in the $V_{\text {OC }}$ would be recorded [26]. In fact this small increase in the $V_{\text {OC }}$ can also be attributed to increase in the quasi-Fermi level of the $\mathrm{TiO}_{2}$ which happens as a consequence of reduced density of surface trap states of the titania [25]. Nevertheless, at this point we can rule out the injection efficiency as the dominant contributor to the improvement in the current density.

We recorded the open circuit voltage decay (OCVD) of the solar cells with and without a surface treatment to investigate in-depth mechanism behind the efficiency improvement in using the colloidal treatment and annealing at $450^{\circ} \mathrm{C}$. This technique in principle is a large perturbation technique used to extract information on the recombination time and mechanism in the DSSC. The cell is illuminated under steady state conditions and after the light is switched off, the $V_{\text {OC }}$ decay is measured. The OCVD technique is a dark measurement, meaning that the recombination with the dye is not registered. Additionally it is important to point out that OCVD measurement time frame in liquid DSSCs is quite long $(>50 \mathrm{~ms})$ so only information on the recombination of the electrons with the oxidized electrolyte is measured. Since the electron transport in the $\mathrm{TiO}_{2}$ mesoporous photoanode has been explained vastly by a trapping/detrapping model [36-38], Bisquert and coworkers have developed interpretation of the electron lifetime measured by OCVD that considers not only the trapping/detrapping events in the semiconductor but also the different possibilities for interfacial charge transfer [39, 40]. Figure 6(a) shows the decay curves of the cells prepared with and without the colloidal treatment of the photoanode. It can be seen that the $V_{\mathrm{OC}}$ of the cell with posttreated photoanode has a slower initial decay, which continues with time to decay in a similar way as the cell with the untreated photoanode. The steeper 


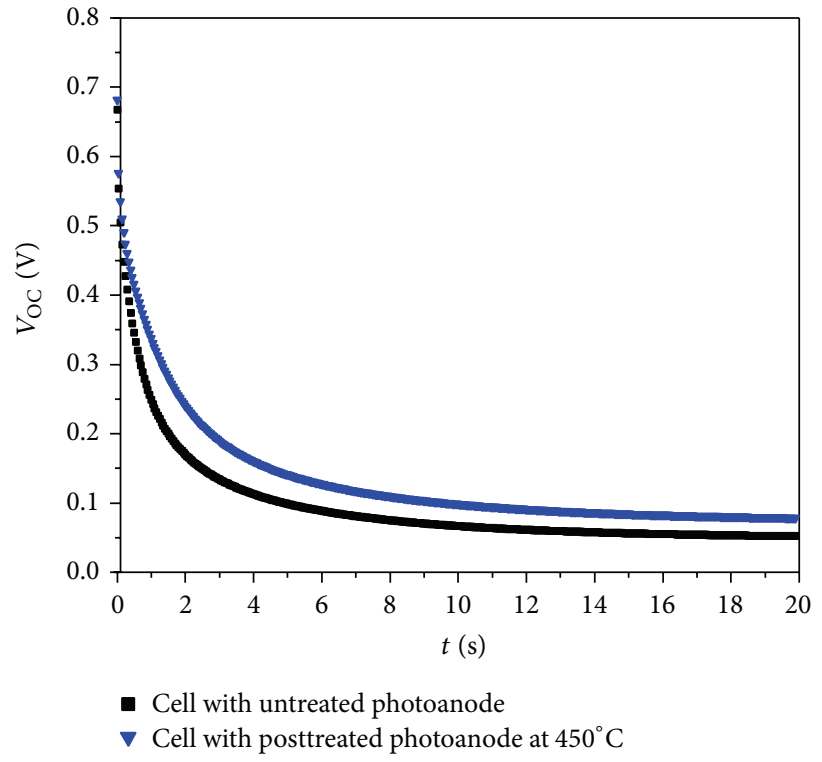

(a)

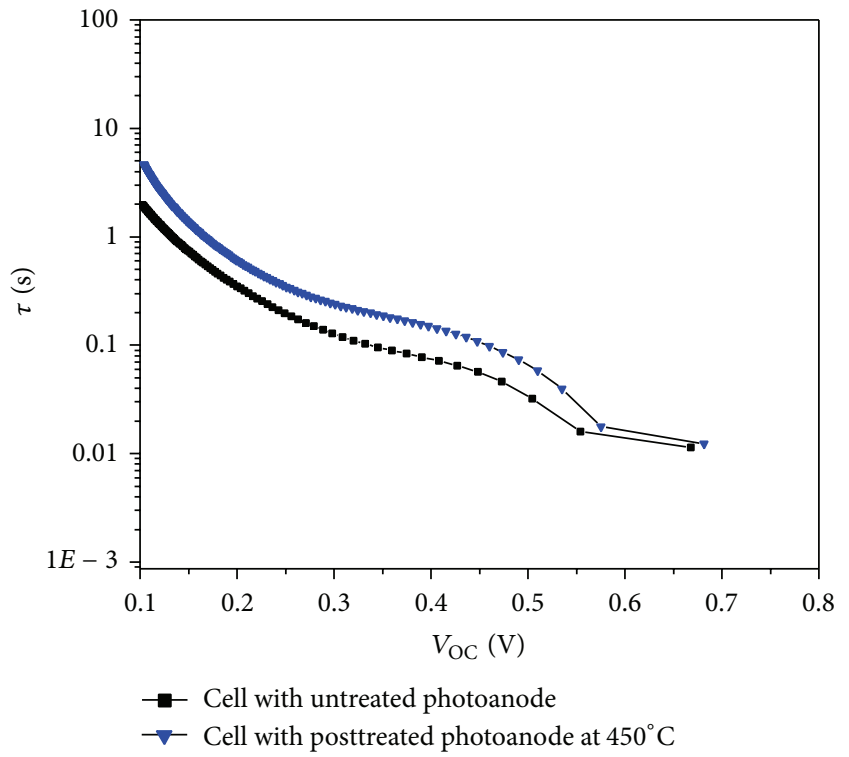

(b)

Figure 6: (a) Open circuit voltage decay curves; (b) electron lifetime as a function of the $V_{\text {OC }}$, of DSSC with untreated photoanode (black full square) and posttreated photoanode with colloidal treatment at $450^{\circ} \mathrm{C}$ (blue full inverted triangle).

decay of the cell with untreated photoanode is an indication of faster recombination of the electrons with the oxidized species in the electrolyte. According to the theory [39] the electron lifetime $\tau$ can be derived from the derivative of the $V_{\mathrm{OC}}$ decay curve using the following expression:

$$
\tau=-\left(\frac{k_{b} T}{e}\right) *\left(\frac{d V_{\mathrm{OC}}}{d t}\right)^{-1}
$$

where $k_{b}$ is the Boltzmann constant, $T$ is the absolute temperature, $e$ is the elementary charge, and $t$ is the elapsed time.

The $\log \tau_{n}-V_{\mathrm{OC}}$ curve has 3 characteristic regions, which give information on the electronic states involved in the recombination process. A constant electron lifetime at high $V_{\mathrm{OC}}$ indicates recombination via free electrons in the conduction band; a linear increase in the mid $V_{\mathrm{OC}}$ region is a sign of trapping/detrapping events where charge transfer is mainly governed through bulk traps, and a region of inverted parabola in the low $V_{\mathrm{OC}}$ indicates a change in the trap states responsible for the recombination from bulk to surface states [40].

From the two curves in Figure 6(b) it is evident that there is a very small region of seemingly constant lifetime at high $V_{\mathrm{OC}}$ around $0.7 \mathrm{~V}$. In this region there is practically no difference between the two cells. Analyzing the shape of the curves we can notice that there is a more significant difference in the electron lifetime of the two cells in the region where the charge transport is governed by processes of trapping and detrapping. The relatively linear part up to $V_{\mathrm{OC}} \sim 0.45 \mathrm{~V}$ suggests that, at this position of the Fermi level, the transfer occurs mainly through bulk traps in the $\mathrm{TiO}_{2}$. The onset of the parabolic shape of the curve for the cell with the posttreated photoanode is slightly shifted towards lower potentials which signifies the beginning of recombination processes dominated by surface states. Charge transfer is realized through bulk trap states up to lower values of the potential compared to the cell with the untreated photoanode. It would seem that the mechanism of increasing the efficiency of the cell is in fact determined by the decrease of surface trap states. By modifying the surface trap density one can manage to reduce the charge transport through the surface states and increase the electron lifetime of the $\mathrm{TiO}_{2}$ photoanode and consequently reduce the recombination probability. This increase in the electron lifetime can be the reason behind the efficiency increase.

Since there have been reports in the literature that the recombination kinetics between the $\mathrm{TiO}_{2}$ photoanode and the electrolyte might be dependent on the ionic liquid in the electrolyte [41, 42], we have performed OCVD measurements on solar cells with commercially available Solaronix electrolyte, without the intention of investigating how concentration, diffusion coefficient of the triiodide, or different cations affect the recombination, but rather just to confirm that the surface treatment is reducing the surface states of the $\mathrm{TiO}_{2}$ mesoporous film, and in doing so reducing the interfacial recombination regardless of the electrolyte. The cell size, assembly and all other materials and parameters were as described previously in Section 2.2.

In Figure 7(a) we are showing the electron lifetime dependence on the open circuit voltage of these cells. The shape of the curves emphasizes the difference in the recombination mechanism even more significantly. At high $V_{\mathrm{OC}}$ the electron transport through the conduction band is demonstrated with the seemingly constant electron lifetime. The exponential increase of the lifetime represented with the straight line 


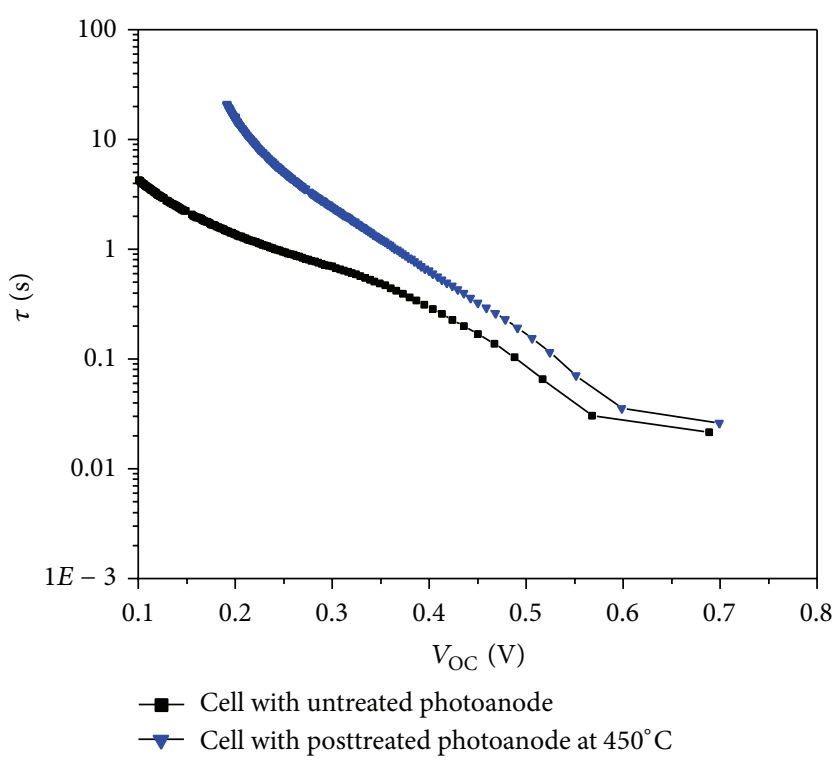

(a)

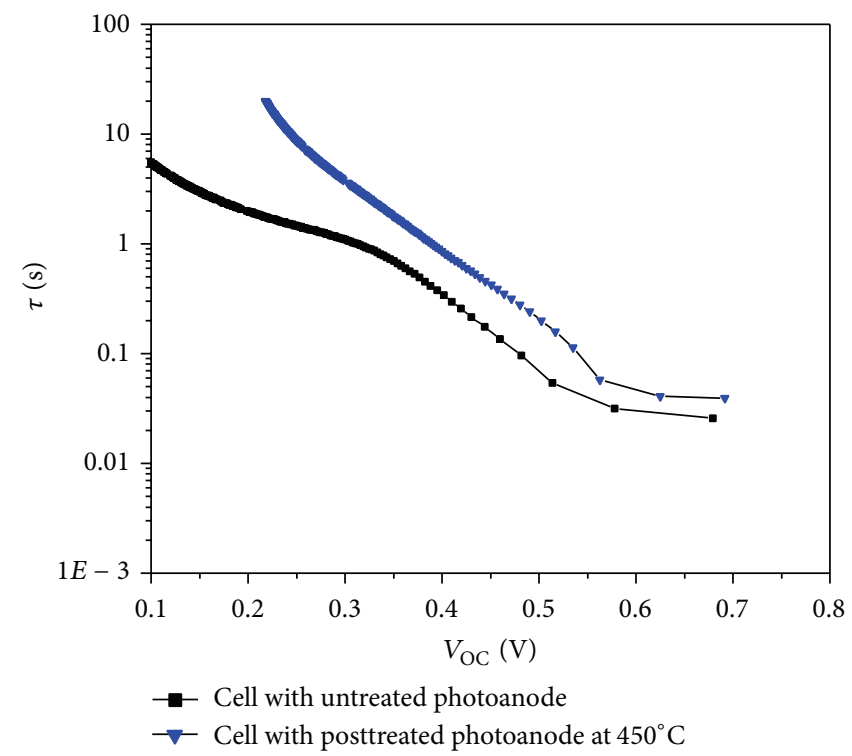

(b)

FIGURE 7: Electron lifetime as a function of the $V_{\mathrm{OC}}$ of DSSC with untreated photoanode (black full square) and posttreated photoanode with colloidal treatment at $450^{\circ} \mathrm{C}$ (blue full inverted triangle), with Solaronix electrolyte: (a) without a compact layer; (b) with a compact layer.

in the logarithmic representation follows the same trend of trap-facilitated transport as described from the curves in Figure 6(b). However at $V_{\mathrm{OC}}<0.4 \mathrm{~V}$ for the untreated electrode there is an onset of parabolic curvature which indicates that recombination through surface traps becomes dominant, whereas for the posttreated electrode this onset begins at around $0.25 \mathrm{~V}$. Because the transport mainly occurs through bulk trap states, the recombination time is prolonged by one order of magnitude considering that the electrons are caught and released much faster from surface than from bulk trap states. This type of lifetime dependence points out that surface traps have been significantly diminished.

In contrast to the $\tau_{n}\left(V_{\mathrm{OC}}\right)$ curve shape of the cells with ionic liquid electrolyte presented in Figure 6(b), the curves in Figure 7(a) are quite different. Explicitly this difference is evident in the lower electron lifetime and the more pronounced inverted parabola shape in the low $V_{\mathrm{OC}}$ region. The lower electron lifetime can be attributed to the higher thickness of the mesoporous photoanode. Because of the grater surface area and the larger number of grain boundaries, a more intense electron recombination due to a higher surface states density can be expected. The shape of the inverted parabola region is determined mainly by the reorganization energy of the acceptor species in the electrolyte [40]. Furthermore, the combination of different dye and electrolyte components on semiconducting nanocrystals can change the density of surface states [43].

According to Cameron and Peter [44], it is essential to also take into account the recombination with the electrolyte through the substrate when analyzing the OCVD curves. Since no surface treatment is made on the substrate in the preparation of the different photoanodes and the investigation is focused on the surface treatment of the photoanode without changing the electrolyte within the same batch of cells, for the purposes of analyzing the charge transfer through different trap states, we tend not to take into account the back reaction via the substrate, given that the effects of this reaction should be the same in all the cells. Additionally our investigation is not focused on analytically deriving the density of states function but rather extracting information on how the surface treatment influences the electron lifetime; hence we believe that it is appropriate to use the previously discussed methodology $[39,40]$. However with the intention of confirming the validity of our results, we have prepared identical cells, to those measured in Figure 7(a), with the only difference of adding a compact $\mathrm{TiO}_{2}$ layer. The results are shown in Figure 7(b). It is evident that using a compact layer does not significantly change the shape of the $\tau_{n}\left(V_{\mathrm{OC}}\right)$ curve.

Again, we can confirm that the main difference in the electron lifetime is due to the reduction of the surface state transport. When comparing the shape of the curves presented in Figures 7(a) and 7(b) one can observe that the cells employing a $\mathrm{TiO}_{2}$ compact layer and the ones without the compact layer have almost identical $\tau_{n}\left(V_{\mathrm{OC}}\right)$ curve shape.

\section{Conclusions}

The implementation of $\mathrm{TiO}_{2}$ nanoparticle colloidal solution for posttreatment of the dye-sensitized solar cell photoanode has proven to be favorable in efficiency improvement. We have investigated the posttreatment sintering temperature dependence on the morphological properties of the photoanode films as well as the impact on the photovoltaic properties of the DSSC. Establishing an efficiency improvement of $10 \%$ for the photoanode posttreated with the colloidal solution of anatase nanoparticles at $450^{\circ} \mathrm{C}$, we further investigated 
the mechanisms responsible for this efficiency increase. The recorded efficiency increase was mostly a result of an increase in the short circuit current; however we saw no evidence of an increase of the effective surface area of the posttreated photoanode or an increased dye loading. From the conducted investigation by OCVD measurements we can validate that this type of colloidal treatment of the mesoporous photoanode reduces the number of surface traps that can act as recombination centers, hence prolonging the electron lifetime. The posttreatment nanoparticle layer operates in a manner of passivating the surface of the photoanode altering the recombination mechanism by shifting the bulk trap state dominant transport to lower potentials.

The colloidal treatment not only increases the overall cell efficiency similarly to the $\mathrm{TiCl}_{4}$, but also represents a facile method for posttreatment that leads to further cost beneficial manufacturing of the dye-sensitized solar cell.

\section{Conflict of Interests}

The authors declare that there is no conflict of interests regarding the publication of this paper.

\section{Acknowledgments}

The authors wish to thank Dr. Caterina Soldano and Mr. Paolo Mei for the precious technical contribution. This work was partially supported by Progetto Premiale CNR 2012Produzione di energia da fonti rinnovabili (Iniziativa CNR per il Mezzogiorno, L. 191/2009 art. 2 comma 44).

\section{References}

[1] B. O'Regan and M. Grätzel, "A low-cost, high-efficiency solar cell based on dye-sensitized colloidal $\mathrm{TiO}_{2}$ films," Nature, vol. 353, pp. 737-740, 1991.

[2] M. A. Green, K. Emery, Y. Hishikawa, W. Warta, and E. D. Dunlop, "Solar cell efficiency tables," Progress in Photovoltaics: Research and Applications, vol. 21, no. 5, pp. 827-837, 2013.

[3] J. Krüger, U. Bach, and M. Grätzel, "Modification of $\mathrm{TiO}_{2}$ heterojunctions with benzoic acid derivatives in hybrid molecular solid-state devices," Advanced Materials, vol. 12, no. 6, pp. 447451, 2000.

[4] C. Hsu, Y. Chen, R. Y. Lin, K. Ho, and J. T. Lin, "Solidstate dye-sensitized solar cells based on spirofluorene (spiroOMeTAD) and arylamines as hole transporting materials," Physical Chemistry Chemical Physics, vol. 14, no. 41, pp. 1409914109, 2012.

[5] M. M. Lee, J. Teuscher, T. Miyasaka, T. N. Murakami, and H. J. Snaith, "Efficient hybrid solar cells based on mesosuperstructured organometal halide perovskites," Science, vol. 338, no. 6107, pp. 643-647, 2012.

[6] J. Burschka, N. Pellet, S. Moon et al., "Sequential deposition as a route to high-performance perovskite-sensitized solar cells," Nature, vol. 499, no. 7458, pp. 316-319, 2013.

[7] L. Qi, J. D. Sorge, and D. P. Birnie III, "Dye-sensitized solar cells based on $\mathrm{TiO}_{2}$ coatings with dual size-scale porosity," Journal of the American Ceramic Society, vol. 92, no. 9, pp. 1921-1925, 2009.

[8] L. de Marco, M. Manca, R. Buonsanti et al., "High-quality photoelectrodes based on shape-tailored $\mathrm{TiO}_{2}$ nanocrystals for dye-sensitized solar cells," Journal of Materials Chemistry, vol. 21, no. 35, pp. 13371-13379, 2011.

[9] Y. Ooyama and Y. Harima, "Photophysical and electrochemical properties, and molecular structures of organic dyes for dyesensitized solar cells," ChemPhysChem, vol. 13, no. 18, pp. 40324080, 2012.

[10] M. J. Griffith, K. Sunahara, P. Wagner et al., "Porphyrins for dyesensitised solar cells: new insights into efficiency-determining electron transfer steps," Chemical Communications, vol. 48, no. 35, pp. 4145-4162, 2012.

[11] A. Yella, H. W. Lee, H. N. Tsao et al., "Porphyrin-sensitized solar cells with cobalt (II/III)-based redox electrolyte exceed 12 percent efficiency," Science, vol. 334, no. 6056, pp. 629-634, 2011.

[12] A. Abate, T. Leijtens, S. Pathak et al., "Lithium salts as "redox active" p-type dopants for organic semiconductors and their impact in solid-state dye-sensitized solar cells," Physical Chemistry Chemical Physics, vol. 15, no. 7, pp. 2572-2579, 2013.

[13] X. Dang, H. Yi, M. Ham et al., "Virus-templated self-assembled single-walled carbon nanotubes for highly efficient electron collection in photovoltaic devices," Nature Nanotechnology, vol. 6, no. 6, pp. 377-384, 2011.

[14] G. H. Guai, Y. Li, C. M. Ng, C. M. Li, and M. B. Chan-Park, " $\mathrm{TiO}_{2}$ composing with pristine, metallic or semiconducting single-walled carbon nanotubes: which gives the best performance for a dye-sensitized solar cell," ChemPhysChem, vol. 13, no. 10, pp. 2566-2572, 2012.

[15] M.-J. Jeng, Y.-L. Wung, L.-B. Chang, and L. Chow, "Particle size effects of $\mathrm{TiO}_{2}$ on the solar efficiency of dye-sensitized solar cells," International Journal of Photoenergy, vol. 2013, Article ID 563897, 9 pages, 2013.

[16] M. Dubey, M. Shrestha, Y. Zhong, D. Galipeau, and H. He, " $\mathrm{TiO}_{2}$ nanotube membranes on transparent conducting glass for high efficiency dye-sensitized solar cells," Nanotechnology, vol. 22, no. 28, Article ID 285201, 2011.

[17] E. J. W. Crossland, N. Noel, V. Sivaram, T. Leijtens, J. A. Alexander-Webber, and H. J. Snaith, "Mesoporous $\mathrm{TiO}_{2}$ single crystals delivering enhanced mobility and optoelectronic device performance," Nature, vol. 495, no. 7440, pp. 215-219, 2013.

[18] E. Palomares, J. N. Clifford, S. A. Haque, T. Lutz, and J. R. Durrant, "Control of charge recombination dynamics in dye sensitized solar cells by the use of conformally deposited metal oxide blocking layers," Journal of the American Chemical Society, vol. 125, no. 2, pp. 475-482, 2003.

[19] F. Fabregat-Santiago, J. García-Cañadas, E. Palomares et al., "The origin of slow electron recombination processes in dyesensitized solar cells with alumina barrier coatings," Journal of Applied Physics, vol. 96, no. 11, pp. 6903-6907, 2004.

[20] M. Zalas and M. Klein, "The influence of titania electrode modification with lanthanide ions containing thin layer on the performance of dye-sensitized solar cells," International Journal of Photoenergy, vol. 2012, Article ID 927407, 8 pages, 2012.

[21] T. C. Li, M. S. Góes, F. Fabregat-Santiago et al., "Surface passivation of nanoporous $\mathrm{TiO}_{2}$ via atomic layer deposition of $\mathrm{ZrO}_{2}$ for solid-state dye-sensitized solar cell applications," Journal of Physical Chemistry C, vol. 113, no. 42, pp. 18385-18390, 2009.

[22] M. Wang, X. Li, H. Lin, P. Pechy, S. M. Zakeeruddin, and M. Grätzel, "Passivation of nanocrystalline $\mathrm{TiO}_{2}$ junctions by surface adsorbed phosphinate amphiphiles enhances the photovoltaic performance of dye sensitized solar cells," Dalton Transactions, no. 45, pp. 10015-10020, 2009. 
[23] W. Xu, S. Dai, L. Hu et al., "Influence of different surface modifications on the photovoltaic performance and dark current of dye-sensitized solar cells," Plasma Science and Technology, vol. 9, no. 5, pp. 556-559, 2007.

[24] L. Vesce, R. Riccitelli, G. Soscia, T. M. Brown, A. Di Carlo, and A. Reale, "Optimization of nanostructured titania photoanodes for dye-sensitized solar cells: Study and experimentation of TiCl4 treatment," Journal of Non-Crystalline Solids, vol. 356, no. 37-40, pp. 1958-1961, 2010.

[25] S.-W. Lee, K.-S. Ahn, K. Zhu, N. R. Neale, and A. J. Frank, "Effects of $\mathrm{TiCl}_{4}$ treatment of nanoporous $\mathrm{TiO}_{2}$ films on morphology, light harvesting, and charge-carrier dynamics in dye-sensitized solar cells," The Journal of Physical Chemistry C, vol. 116, no. 40, pp. 21285-21290, 2012.

[26] P. M. Sommeling, B. C. O’Regan, R. R. Haswell et al., "Influence of a $\mathrm{TiCl}_{4}$ post-treatment on nanocrystalline $\mathrm{TiO}_{2}$ films in dyesensitized solar cells," The Journal of Physical Chemistry B, vol. 110, no. 39, pp. 19191-19197, 2006.

[27] B. C. O’Regan, J. R. Durrant, P. M. Sommeling, and N. J. Bakker, "Influence of the $\mathrm{TiCl}_{4}$ treatment on nanocrystalline $\mathrm{TiO}_{2}$ films in dye-sensitized solar cells. 2. Charge density, band edge shifts, and quantification of recombination losses at short circuit," Journal of Physical Chemistry C, vol. 111, no. 37, pp. 14001-14010, 2007.

[28] S. Ito, P. Liska, P. Comte et al., "Control of dark current in photoelectrochemical $\left(\mathrm{TiO}_{2} / \mathrm{I}^{-}-\mathrm{I}_{3}^{-}\right)$and dye-sensitized solar cells," Chemical Communications, no. 34, pp. 4351-4353, 2005.

[29] T. Rajh, A. E. Ostafin, O. I. Micic, D. M. Tiède, and M. C. Thurnauer, "Surface modification of small particle $\mathrm{TiO}_{2}$ colloids with cysteine for enhanced photochemical reduction: an EPR study," The Journal of Physical Chemistry, vol. 100, no. 11, pp. 4538-4545, 1996.

[30] R. C. Thompson, "Oxidation of peroxotitanium(IV) by chlorine and cerium(IV) in acidic perchlorate solution," Inorganic Chemistry, vol. 23, no. 13, pp. 1794-1798, 1984.

[31] G. H. Jeffery, J. Bassett, J. Mendham, and R. C. Denney, Vogel's Textbook of Quantitative Chemical Analysis, Wiley, New York, NY, USA, 5th edition, 1989.

[32] S. Kelly, F. H. Pollak, and M. Tomkiewicz, "Raman spectroscopy as a morphological probe for $\mathrm{TiO}_{2}$ aerogels," The Journal of Physical Chemistry B, vol. 101, no. 14, pp. 2730-2734, 1997.

[33] T. Trupke, P. Würfel, and I. Uhlendorf, "Dependence of the photocurrent conversion efficiency of dye-sensitized solar cells on the incident light intensity," Journal of Physical Chemistry B, vol. 104, no. 48, pp. 11484-11488, 2000.

[34] D. Zhang, J. A. Downing, F. J. Knorr, and J. L. McHale, "Roomtemperature preparation of nanocrystalline $\mathrm{TiO}_{2}$ films and the influence of surface properties on dye-sensitized solar energy conversion," Journal of Physical Chemistry B, vol. 110, no. 43, pp. 21890-21898, 2006.

[35] W. Liu, L. Hu, S. Dai, L. Guo, N. Jiang, and D. Kou, "The effect of the series resistance in dye-sensitized solar cells explored by electron transport and back reaction using electrical and optical modulation techniques," Electrochimica Acta, vol. 55, no. 7, pp. 2338-2343, 2010.

[36] J. van de Lagemaat and A. J. Frank, "Nonthermalized electron transport in dye-sensitized nanocrystalline $\mathrm{TiO}_{2}$ films: transient photocurrent and random-walk modeling studies," The Journal of Physical Chemistry B, vol. 105, no. 45, pp. 11194-11205, 2001.
[37] J. A. Anta, J. Nelson, and N. Quirke, "Charge transport model for disordered materials: application to sensitized $\mathrm{TiO}_{2}$," Physical Review B, vol. 65, Article ID 125324, 10 pages, 2002.

[38] A. J. Frank, N. Kopidakis, and J. V. D. Lagemaat, "Electrons in nanostructured $\mathrm{TiO}_{2}$ solar cells: transport, recombination and photovoltaic properties," Coordination Chemistry Reviews, vol. 248, no. 13-14, pp. 1165-1179, 2004.

[39] A. Zaban, M. Greenshtein, and J. Bisquert, "Determination of the electron lifetime in nanocrystalline dye solar cells by opencircuit voltage decay measurements," ChemPhysChem, vol. 4, no. 8, pp. 859-864, 2003.

[40] J. Bisquert, A. Zaban, M. Greenshtein, and I. Mora-Seró, "Determination of rate constants for charge transfer and the distribution of semiconductor and electrolyte electronic energy levels in dye-sensitized solar cells by open-circuit photovoltage decay method," Journal of the American Chemical Society, vol. 126, no. 41, pp. 13550-13559, 2004.

[41] S. Kambe, S. Nakade, T. Kitamura, Y. Wada, and S. Yanagida, "Influence of the electrolytes on electron transport in mesoporous $\mathrm{TiO}_{2}$-electrolyte systems," Journal of Physical Chemistry $B$, vol. 106, no. 11, pp. 2967-2972, 2002.

[42] S. Nakade, T. Kanzaki, W. Kubo, T. Kitamura, Y. Wada, and S. Yanagida, "Role of electrolytes on charge recombination in dyesensitized $\mathrm{TiO}_{2}$ solar cell (1): the case of solar cells using the $\mathrm{I}^{-} / \mathrm{I}_{3}^{-}$redox couple," Journal of Physical Chemistry B, vol. 109, no. 8, pp. 3480-3487, 2005.

[43] R. Li, J. Liu, N. Cai, M. Zhang, and P. Wang, "Synchronously reduced surface states, charge recombination, and light absorption length for high-performance organic dye-sensitized solar cells," The Journal of Physical Chemistry B, vol. 114, no. 13, pp. 4461-4464, 2010.

[44] P. J. Cameron and L. M. Peter, "How does back-reaction at the conducting glass substrate influence the dynamic photovoltage response of nanocrystalline dye-sensitized solar cells?" Journal of Physical Chemistry B, vol. 109, no. 15, pp. 7392-7398, 2005. 

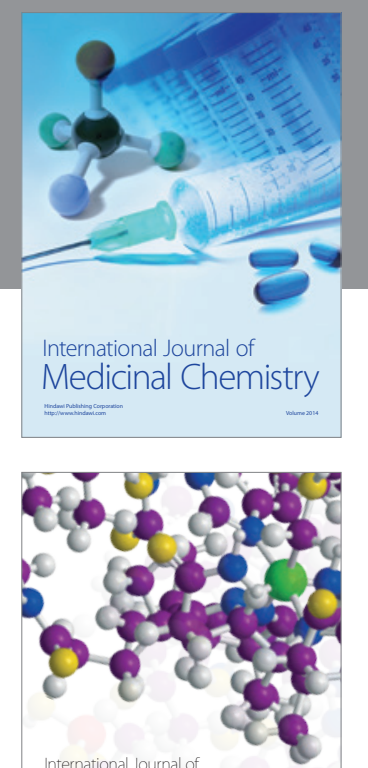

\section{Carbohydrate} Chemistry

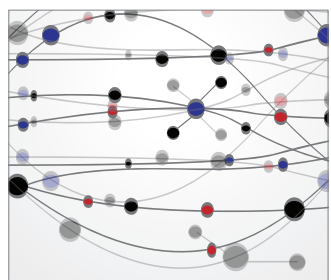

The Scientific World Journal
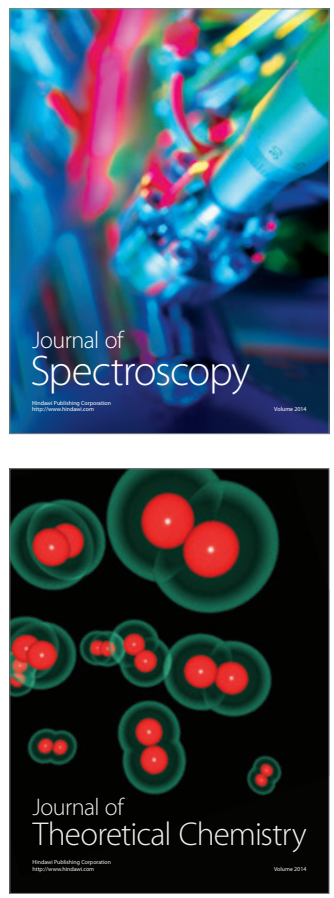
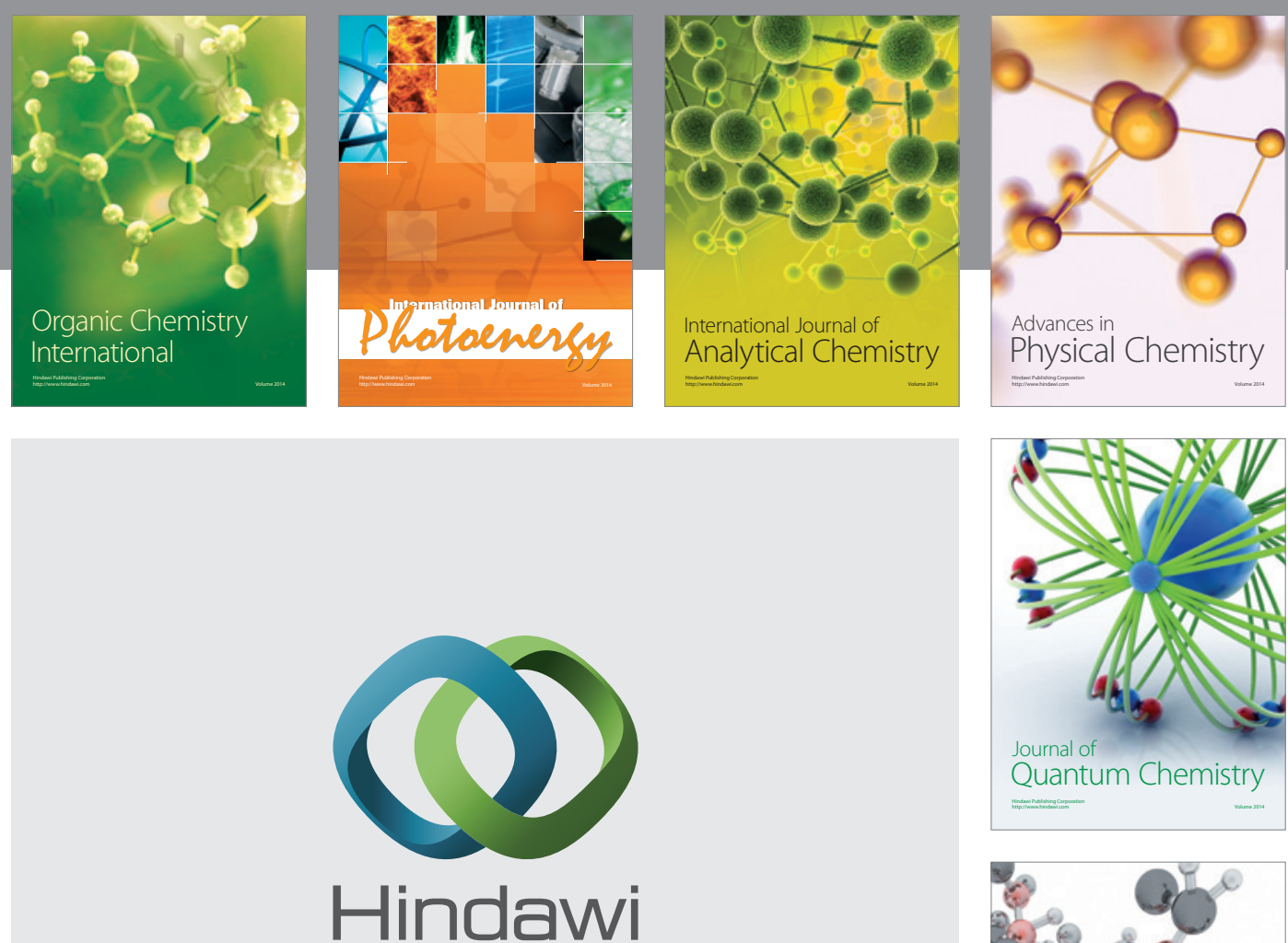

Submit your manuscripts at

http://www.hindawi.com

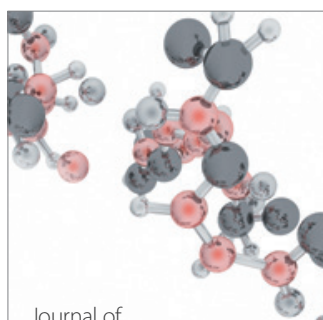

Analytical Methods

in Chemistry

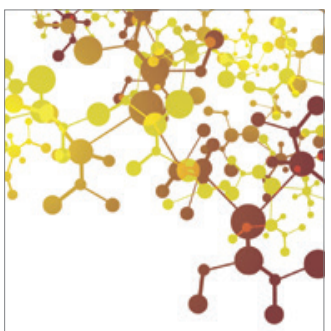

Journal of

Applied Chemistry

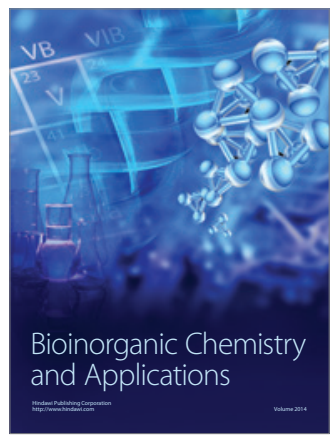

Inorganic Chemistry
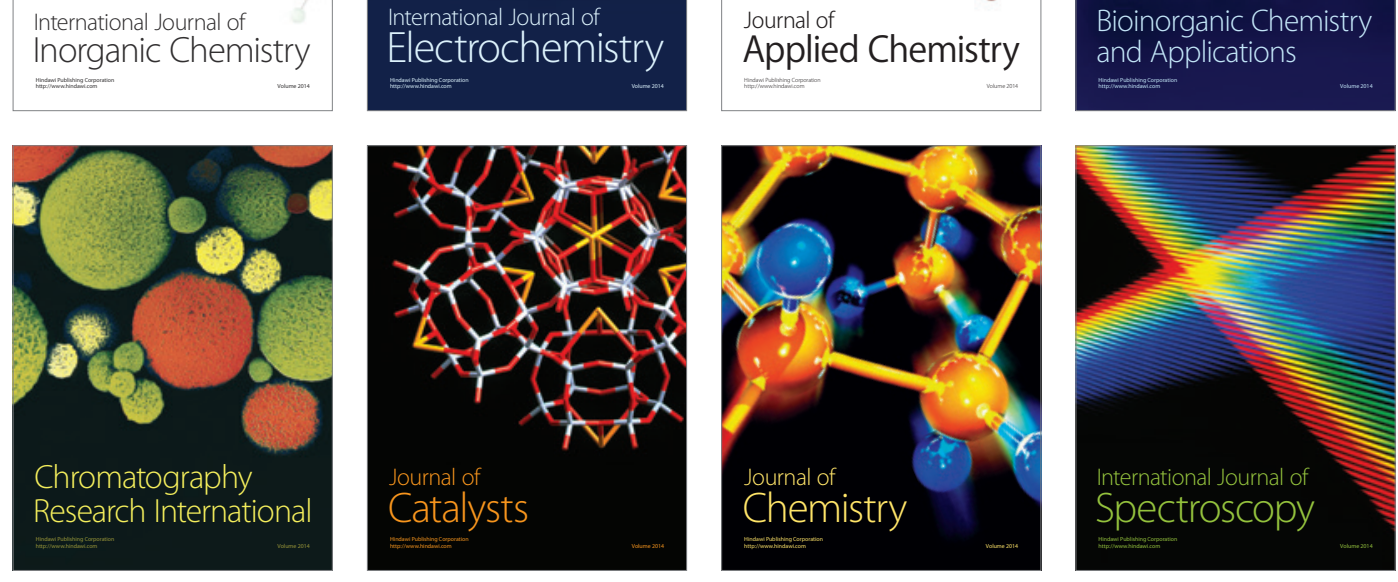